\title{
Evaluation of potential contribution of plant growth-promoting bacteria to land desertification
}

\author{
Min $\mathrm{He}^{1, *}$ \\ ${ }^{1}$ School of the Environment and Safety Engineering, Jiangsu University, Zhenjiang 212013, PR China
}

\begin{abstract}
The problem of soil degradation is becoming more and more serious, how to effectively repair desertified degraded soil has aroused widespread concern. As one of the emerging strategies, plant restoration has great advantages such as high efficiency and low cost, but this technology also has some defects, that is, it is difficult for plants to be established in the coercive environment of ecological destruction. Modified plant growth-promoting bacteria (PGPB) is usually used to increase crop yield. In addition to their proven uses in agriculture, they also have potential in solving environmental problems. This paper analyzes the limitations of solving the problem of environmental degradation based on phytoremediation, and enumerates and explains two methods for screening PGPB. By enumerating the application status of PGPB in promoting the growth of native plants to prevent soil erosion in degraded areas, the importance of plant growth-promoting bacteria to soil quality and microbial structure before plant remediation was discussed. The purpose of this paper is to provide thoughts and suggestions for the study of phytoremediation by combined plant growth-promoting bacteria and plants in desertified degraded soil environment.
\end{abstract}

\section{Introduction}

Land degradation is a common problem worldwide and is common in arid areas of the southwestern United States, northwestern Mexico and the Andes. By the end of 2009, the total area of desertified land in China was 2.6237 million square kilometers, accounting for $27.33 \%$ of the total land area. It reduces the area of arable land, increases soil erosion and flooding, reduces agricultural and forest production, reduces the rural population, and increases respiratory health caused by dust pollution ((Wang et al., 2004). Traditional chemical fertilizer composting and remediation schemes of polymer materials and humic acid are costly and usually impractical because of the large area of degraded and desertified soil involved. As a result, more cost-effective remediation technologies are being developed. The main factors limiting remediation of stressed environment, such as soil salinization, alkalization and wind-sand drift. Soil salinization, alkalinization and wind-sand drift are the main causes of soil degradation. The stressful environment has led to a massive reduction in crop production and the inability of plants to survive.

Restoration of native vegetation is one of the recommended solutions to combat erosion of soil desertification. However, once the soil characteristics are destroyed, it is difficult to improve, so that the restoration of natural vegetation becomes very slow, or even cannot occur. However, due to the complexity and diversity of the actual environment, the failure of phytoremediation cannot be blamed solely on drought and water shortage. Akiyama and Kawamura confirmed that planting native seeds on disturbed desert land in Arizona can restore vegetation, irrigation increased plant coverage, but it contained up to $50 \%$ of weed seeds, with only $4 \%$ of native grass species [2]. Phytoremediation is one of the emerging strategies. Inoculation of native plants with plant growth-promoting bacteria (PGPB) or arbuscular mycorrhizal fungi can prove to be the best environmental practice for degraded land reclamation.

Plant growth-promoting bacteria (PGPB) are isolated from different environment, which generally directly produce beneficial plant hormones (auxin, gibberellin, iron carrier, etc.) or indirect biological control have a positive impact on plant growth and yield parameters. The mechanism of action of PGPB has been reviewed dialectically in several review articles (Fig. 1). Therefore, the possible mechanism of PGPB promoting plant growth will not be discussed in this review. Inoculating native plants with plant growth-promoting bacteria (PGPB) or arbuscular mycorrhizal fungi (AMF) can be proved to be the best environmental practice for degraded land reclamation. The use of PGPB for vegetation reconstruction has the following benefits: (1) reducing the cost of bioremediation by reducing the amount of fertilizer and composting; (2) allowing the establishment of plants in previously grown degraded areas; and (3) improving

\footnotetext{
*Corresponding author: 2211709005@stmail.ujs.cn
} 
plant health and growth performance in eroded areas and enhancing their tolerance to drought and salinity.

The interaction between plants and their related PGPB has various and complex characteristics, which has become the subject of extensive research and various applications. This paper summarizes the limitations of pure phytoremediation in the environment of desertification and degradation, based on the screening method of PGPB under stress environment, author discusses the important role of PGPB in land desertification degradation, and puts forward some thoughts and suggestions on phytoremediation of desertification degraded soil.

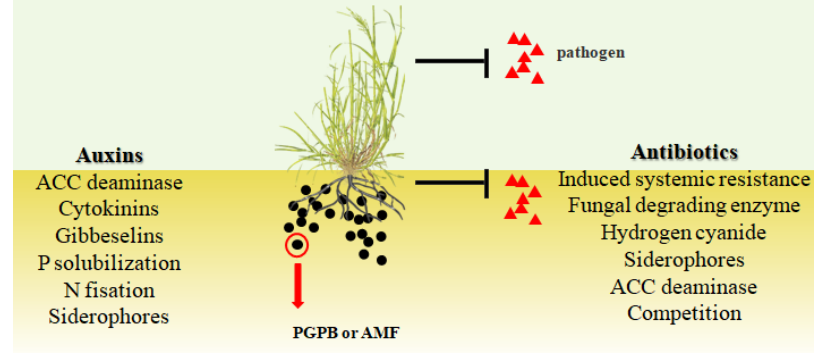

Fig. 1. Mechanism of Plant growth-promoting bacteria.

\section{Limitations of phytoremediation of desertification soil}

Phytoremediation is a long-term process of natural community succession, and it is necessary to establish peak plants in this area. With the coarsening of topsoil grain size (from clay and silt to sand) in the process of soil degradation, not only the soil water retention capacity and soil organic matter are reduced, but also the species composition, species diversity, coverage and structure of vegetation are changed [1]. As a result, few plant species can be established in arid and barren stress environment. In the desert "resource island", nursing plants such as mesquite trees can provide fertility for restoration plants (high organic matter, high water holding capacity, etc.). Mesquite trees - Cactus is a famous seedling combination. In the early years, mesquite trees (such as $P$. artiulata) were much larger than young cacti, grew cactus seedlings under their canopies, and cacti had easier access to water under the canopy. Mesquite trees can prevent soil erosion for years or decades until cacti eventually replace them and will stabilize the soil for centuries. However, most of the nature conservation systems in the desert have been destroyed, and the topsoil and microbes have been eroded by wind and water. Therefore, when using plants to repair desertified soil, ecologists often consider adding compost or using polymer materials to provide conservation capacity. However, degraded desertification areas usually involve a wide range of soil areas, such as mine tailings, alpine grasslands, deserts and so on, and the effectiveness of rehabilitation is limited by economic factors (Fig. 2).

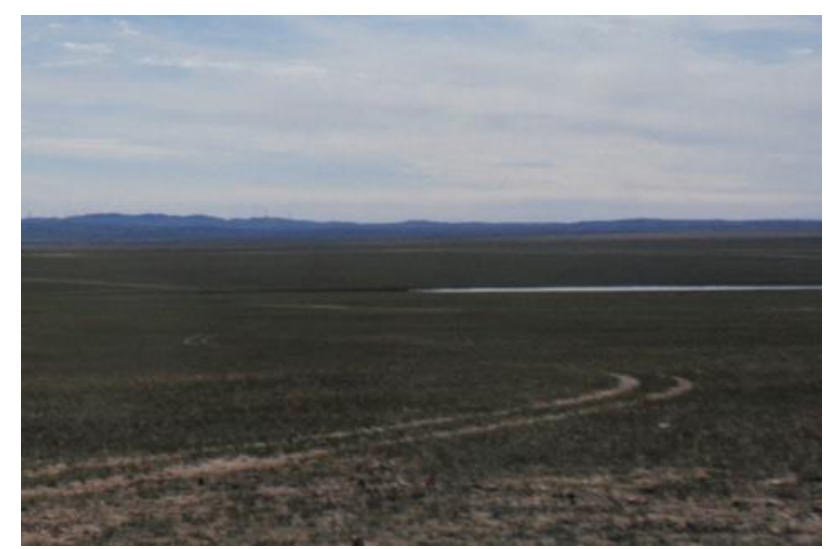

Fig. 2. Large-scale steppe degradation.

One of the basic theories put forward about the repeated failures of phytoremediation in eroded desert areas and the difficulties in establishing local plant populations is that the topsoil loses beneficial plantassociated microorganisms, thus losing part of its fertility and growth potential. This can happen even in years when rainfall is occasionally plentiful, because water does not restore soil fertility, health or microbial community. In summary, the basic plant growth-promoting bacteria (PGPB) should be reintroduced artificially.

\section{Screening of PGPB}

Taking the most widely studied genus (Azospirillum) as an example, Puente M-E found that different PGPB strains, even Azospirillum, had different responses to the growth of desert plant cactus. The selection of PGPB is also slightly different to alleviate environmental stress in different degraded areas, such as drought stress soil. Screening Pseudomonas aeruginosa with the function of producing ACC deaminase can effectively improve the drought tolerance of pea seedlings. Under salt stress and low phosphorus stress, inoculation of Azotobacter chroococcum 76A could promote the growth of tomato plants under moderate and severe salt stress, and improve the stress resistance and nutrient assimilation efficiency of tomato [2].

Screening PGPB compatible with degraded and desertified areas. Two strategies are generally used: one is to examine a large number of available and validated isolates of PGPB strains, which are mainly used in agriculture and used as inoculants in vegetation restoration. The other is the isolation of potential PGPB, from native degraded soil nearby plants rhizosphere. According to , the PGPB known to be effective in the agricultural environment was investigated, several potential strains were isolated and purified, and then laboratory-scale PGPB screening was carried out. Finally, greenhouse screening study was carried out to determine the successful candidates. Three strains (Pseudomonas sp. RJ15, Bacillus subtilis RJ46, Ochrobactrum pseudogrignonense RJ12,) producing ACC deaminase were successfully isolated from the rhizosphere soil of native plants in arid areas. It was proved that the three PGPB complexes may be effective biological agents to improve the health of acid farmland crops affected by 
drought [3]. Although this method has been successfully used to target strains that adapt to arid ecosystems and can survive in stressful tailings environments, it is laborintensive.

The effectiveness of each remediation scheme is not only related to specific combinations of plant species, but also closely related to the environment in which they interact. Therefore, the combination of plant growthpromoting bacteria and remediation plants verified by single screening is not a universal combination of all environmental remediation. Similar to desert recovery, Quoreshi et al. (2008) the selective effect of microbial modifiers was demonstrated when coniferous and broadleaved trees in Canada were inoculated with several mycorrhizal fungi in the nursery. three species of arbuscular mycorrhizal fungi (Glomus clarum, Glomus inaradices and Glomus etunicatum) and three strains of nitrogen-fixing bacteria--two strains of rhizobium (Rhizobium spp.). And a strain of Burkholderia (Burkholderia sp.). When co-inoculated, it showed a similar selection effect on tropical legume trees (Schizolobium Amazonicum), which is commonly used in agroforestry intercropping in Amazon.

\section{Application status of PGPB- phytoremediation}

Efforts to restore degraded dry land by inoculating microbial plants have been carried out in different countries around the world before. In the southwestern United States, Azospirillum brasilense and Bacillus pumilus significantly promoted the growth and development of Atriplex lentiformis on drought environmental [4]. In Spain, combining PGPB, AMF and rhizobium is widely used to promote plant growth in arid areas [5]. Native trees inoculated with PGPB complex in India perform well in degraded park soil. In the Sonoran Desert in southern Mexico and Argentina, inoculation of A. brasilense has greatly promoted the growth, establishment and survival of several mesquite trees and cacti [6]. However, Carrillo-Garcia et al. found that $A$. brasilense had no effect on the growth of giant cactus in the fertile soil of Resource Island. In the worst soil, the dry branch mass increased by $60 \%$ and the root length increased by $100 \%$. And, when A. brasilense was combined with compost as inoculant to simulate resourcebased island soil, the effect of inoculation was smaller than that of compost. At the same time, it was proved by experiments that PGPB treatment was not significant when the amount of compost was high. These studies emphasize the importance of assessing soil quality before PGPB vaccination.

Cactus can be used as one of the most important soil stabilizers in Sonoran Desert, because it has a superficial root system, which is of great significance for stabilizing topsoil. This may be one of the reference indicators for us to choose desert control plants. Although the additional treatment of compost and PGPB is indispensable for the survival and development of unprotected cactus, in the long run, the effect of legumes on the development of cactus is more important than any PGPB treatment when planting seedlings. In addition, over time, even plants that are not vaccinated with AMF become mycorrhizal because there is a sufficient original AMF [7]. The additional treatment has a synergistic effect only in the presence of the most common cactus conservation plants. Monitoring of naturally available substrates in restoration areas, such as resource island soil (or stored in conservation plants), are used to a limited extent during the most critical early growth stages to promote plant survival.

A large number of studies have shown that if native plants are inoculated with PGPB or AMF, the restoration rate of degraded arid soil is accelerated, and the soil health index is improved. It is well known that soil microbial abundance can be changed by directly adding PGPB, which is directly beneficial to soil microbial community structure, and Phylum Actinomycetes is an index of soil degradation. Galaviz et al. showed that the inoculation of Bacillus pumilus ES4 isolated from cactus rhizosphere was beneficial to the remediation of degraded sandy soil, and the abundance of Phylum Proteus and Acidobacteria in plant rhizosphere increased significantly, while the abundance of Actinomycetes decreased significantly, while non-rhizosphere degraded soil showed opposite reaction [8]. On the other hand, inoculate Azospirillum spp. in fertile agricultural soil. The effect on the microbial community structure in the rhizosphere of maize and tomato was negligible [9], which was mainly due to the mass reproduction of other rhizosphere bacteria, that is, $10^{8}-10^{9} \mathrm{CFU} / \mathrm{g}$ culturable bacteria. However, in highly degraded soils, such as unstructured toxic tailings, inoculation of A. brasilense and B. pumilus had significant effects on bacterial community structure [4]. One possible explanation for the difference is that mine tailings contain very low numbers of bacteria, such as $10^{3}-10^{5} \mathrm{CFU} / \mathrm{g}$. Therefore, soil microbial community structure should be monitored and analyzed before plant growth-promoting bacteria assist phytoremediation.

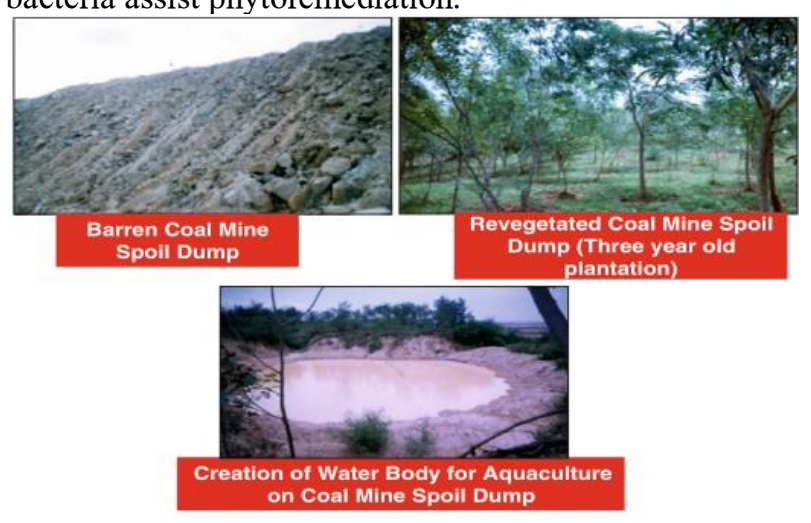

Fig. 3. PGPB-assisted phytoremediation technology for reclamation of coal mine spoil dumps[10].

In short, PGPB plays an irreplaceable role in desertified degraded soil, and has been widely used in fragile habitats such as mine tailings, heavy metal pollution soil, mangrove ecosystem and so on (Fig.3). Screening PGPB that is compatible with degraded environment is a key step in remediation engineering. Monitoring soil quality and screening PGPB for degraded areas under different stress environments are equally 
important for the successful establishment and survival of plants. At the same time, it is of great significance for phytoremediation to excavate and utilize the possible "resource islands" in degraded areas as far as possible.

\section{References}

1. Akiyama T, Kawamura K Grassland Science 53, 1(2007)

2. Van Oosten MJ, Di Stasio E, Cirillo V, Silletti S, Ventorino V, Pepe O, Raimondi G, Maggio A BMC Plant Biol 18, 1(2018)

3. Saikia J, Sarma RK, Dhandia R, Yadav A, Bharali R, Gupta VK, Saikia R Scientific report 8, 3510(2018)

4. de-Bashan LE, Hernandez J-P, Bashan Y, Maier RM Environ Exp Bot 69, 3(2010)
5. Pérez-Fernández MA, Calvo-Magro E, Valentine A Land degradation \& development 27, 2(2016)

6. Bashan Y, Salazar B, Puente ME, Bacilio M, Linderman R Biol Fertility Soils 45, 6(2009)

7. Bashana Y, Davisb EA, Carrillo-Garciaa A, Lindermanb RG Applied Soil Ecology 14 2000(2000)

8. Galaviz C, Lopez BR, de-Bashan LE, Hirsch AM, Maymon M, Bashan Y Land Degradation \& Development 29, 5(2018)

9. Felici C, Vettori L, Giraldi E, Forino LMC, Toffanin A, Tagliasacchi AM, Nuti M Applied Soil Ecology 40, 2(2008)

10. Juwarkar AA Proceedings of the National Academy of Sciences, India Section B: Biological Sciences 82, S2(2012) 